\title{
GMR
}

\section{MicroRNA-139 modulates Alzheimer's- associated pathogenesis in SAMP8 mice by targeting cannabinoid receptor type 2}

\author{
Y. Tang, J.S. Bao, J.H. Su and W. Huang \\ Department of Geriatric, Wuxi No. 2 People's Hospital, Wuxi, Jiangsu, China \\ Corresponding author: W. Huang \\ E-mail: jiaxiya2000@163.com \\ Genet. Mol. Res. 16 (1): gmr16019166 \\ Received September 5, 2016 \\ Accepted December 21, 2016 \\ Published February 16, 2017 \\ DOI http://dx.doi.org/10.4238/gmr16019166 \\ Copyright (C) 2017 The Authors. This is an open-access article distributed under the terms of \\ the Creative Commons Attribution ShareAlike (CC BY-SA) 4.0 License.
}

\begin{abstract}
Alzheimer's disease (AD) is a neurodegenerative disorder, and is the most common type of dementia in the elderly population. Growing evidence indicates that microRNAs (miRNAs) play a crucial role in neuroinflammation associated with $\mathrm{AD}$ progression. In this study, we analyzed the expression of microRNA-139 (miR-139) as well as the learning and memory function in $\mathrm{AD}$. We observed that the miR139 expression was significantly higher in the hippocampus of aged senescence accelerated mouse prone 8 (SAMP8) mice $(2.92 \pm 0.13)$ than in the control mice $(1.49 \pm 0.08)$. Likewise, the overexpression of miR-139 by means of hippocampal injection impaired the hippocampus-dependent learning and memory formation. In contrast, the downregulation of miR-139 in mice improved learning and memory function in the mice. The level of cannabinoid receptor type 2 (CB2), a potential target gene of miR-139, was inversely correlated with the miR-139 expression in primary hippocampal cells. Furthermore, we demonstrated that miR-139 inversely modulated the responses to proinflammatory stimuli. Together, our findings demonstrate that miR-
\end{abstract}

Genetics and Molecular Research 16 (1): gmr16019166 
139 exerts a pathogenic effect in $\mathrm{AD}$ by modulating $\mathrm{CB} 2$-meditated neuroinflammatory processes.

Key words: MicroRNA-139; Alzheimer's disease; Neuroinflammation; Cannabinoid receptor type 2

\section{INTRODUCTION}

Alzheimer's disease (AD) is a chronic neurodegenerative disease and is the most common form of dementia in the world, typically occurring in the seventh decade of life (Burns and Iliffe, 2009; Mendiola-Precoma et al., 2016). AD is characterized by the loss of intellectual and social skills along with impairment of other cognitive functions. Continuous progressive cell death occurs over the course of the disease (Bekris et al., 2010). Due to the increasing number of elderly individuals in the population, it is expected that the number of people who are living with AD worldwide will increase to 114 million by 2050 (Querfurth and LaFerla, 2010). While medication and treatments may temporarily control the symptoms of $\mathrm{AD}$, there is no permanent cure. Therefore, it is important to identify novel therapeutic targets which can effectively slow down or stop the progression of AD.

MicroRNAs (miRNAs) are a novel class of small (18-22 nucleotides long), singlestranded, non-coding RNAs that are essential in the post-transcriptional regulation of gene expression. These RNAs bind to the 3'-untranslated region (3'-UTR) of mRNAs to induce their degradation or translational repression (Abe and Bonini, 2013). Studies have shown that miRNAs play an important role in proliferation, development, apoptosis, inflammation, and malignant diseases (Kim et al., 2009). Growing evidence suggests that the dysregulation of miRNAs is a characteristic of various diseases of the central nervous system, including AD (Hébert and De Strooper, 2009). Moreover, miRNA-targeted treatment approaches have shown enormous potential in controlling the aggressive pathology of AD (Lee et al., 2012; Banzhaf-Strathmann et al., 2014).

The aim of this study was to investigate the role of miR-139 in AD. Here, we chose the senescence accelerated mouse prone 8 (SAMP8) strain as an AD mouse model and the senescence-accelerated mouse-resistant 1 (SAMR1) strain as a control (Wang et al., 2016) strain. First, we measured the expression of miR-139 in the SAMP8 (AD model group) and SAMR1 mice (control group). Next, we examined whether miR-139 affects spatial memory, recognition memory, and contextual fear conditioning by performing hippocampal injection of miRNA/anti-miRNA mimics. Our findings demonstrate that miR-139 regulates hippocampusdependent memory formation by directly targeting CB2, suggesting that miR-139 may be a potential target for $\mathrm{AD}$ diagnosis and therapy.

\section{MATERIAL AND METHODS}

\section{Animals and miRNAs hippocampal injection}

The SAMR1 and SAMP8 mouse strains were obtained from our breeding colonies and maintained as inbred strains from the original breeding pairs provided by the Beijing Vital River Laboratory Animal Limited Company (Beijing, China). The mice were maintained at the Animal Centre of Wuxi No. 2 People's Hospital under a 12-h light/12-h dark cycle at

Genetics and Molecular Research 16 (1): gmr16019166 
$25^{\circ} \mathrm{C}$ with water and food provided ad libitum. The animal experiments were conducted in accordance with the guidelines of Wuxi No. 2 People's Hospital Animal Ethics Committee. The hippocampal injections were performed as described previously (Wang et al., 2016). Briefly, 6-month-old mice received injection of $3 \mathrm{mM}$ miRNA mimics (Genephama, Shanghai, China) into the dentate gyrus by use of a dental drill every week. The subsequent animal experiments were performed two months after the injection.

\section{Morris water maze task}

This experiment was performed as previously described (Ren et al., 2012). The spatial learning and memory were investigated using the Morris water maze hidden platform task. The experiment was conducted using 8 consecutive training days ( 2 training trials per day), in which the time required to escape to the hidden platform was measured. After 8 days of training, the mice were subjected to probe trials on days 1 and 4 post-training. During the probe trials, all the mice were released from the same direction, at which time their movements in the pool were traced for $60 \mathrm{~s}$.

\section{Novel object recognition task}

Forty-four mice were individually habituated to an open-field box for 3 days. During the training period, two novel objects were placed in the open field. The mice were allowed to freely explore the area for $5 \mathrm{~min}$. The time spent exploring each object was recorded. After a specific retention interval ( $1 \mathrm{~h}$ and $1,2,3$, and 4 days), the mice were again placed in the same box, with one of the familiar objects replaced by a new object. The time spent exploring the novel object was expressed as a proportion of the total time spent exploring both the objects.

\section{Contextual fear conditioning task}

The procedure used for contextual fear conditioning was similar to that described in a previous study (Jeon et al., 2003). Briefly, the mice were allowed to explore a novel environment for $3 \mathrm{~min}$, after which time they received a mild electric foot shock $(0.5 \mathrm{~mA}$, constant current, $2 \mathrm{~s}$ ). The percentage of time spent freezing was recorded. Retention tests were conducted $1 \mathrm{~h}$ and 1,3 and 5 days later by reintroducing the mice to the same fearconditioning apparatus chamber and recording the freezing time.

\section{Primary hippocampal cell culture}

Primary hippocampal neurons were grown in culture as described previously (Sang et al., 2005). Briefly, the hippocampi were dissected out from C57BL/6L pups (postnatal day 0 to 1 ), incubated in oxygenated trypsin for $10 \mathrm{~min}$ at $37^{\circ} \mathrm{C}$, and then mechanically triturated. Subsequently, the cells were spun down and resuspended in Neurobasal/B27 medium (Invitrogen, San Diego, CA, USA) supplemented with $0.5 \mathrm{mM}$ L-glutamine, penicillin/ streptomycin, and $25 \mu \mathrm{M}$ glutamate in humidified air at $37^{\circ} \mathrm{C}$ and $5 \% \mathrm{CO}_{2}$. One-third to onehalf of the culture medium without glutamate was changed every 2-3 days. For stimulation, the cells were treated with lipopolysaccharide (LPS; $100 \mathrm{ng} / \mathrm{mL}$ ) (Sigma, St. Louis, MO, USA) and interferon- $\gamma$ (IFN $\gamma ; 20 \mathrm{ng} / \mathrm{mL}$ ) (R\&D Systems, Wiesbaden, Germany) for $12 \mathrm{~h}$.

Genetics and Molecular Research 16 (1): gmr16019166 


\section{Real-time quantitative PCR (RT-PCR)}

Total RNA extraction was performed using the Trizol reagent (TaKaRa, Tokyo, Japan) as per the manufacturer's introduction. A total of 10 ng RNA was converted into cDNA using the miScript Reverse Transcription Kit (Applied Biosystems, Foster City, CA, USA) on an ABI7500 (Life Technologies, Carlsbad, CA, USA). This was followed by RT-PCR detection of the miRNAs using the miScript SYBR-Green PCR Kit (Qiagen) on an ABI7500 (Life Technologies). The relative quantification of miR-139 was calculated using the $2^{-\Delta \Delta \mathrm{Ct}}$ method. The data were normalized using the U6 small nuclear RNA as an internal control and were measured relative to a calibrated sample as the external control.

\section{Western blot assays}

The samples were lysed on ice in RIPA buffer $(150 \mathrm{mM} \mathrm{NaCl}, 1 \%$ TritonX-100, $5 \mathrm{mM}$ EDTA, $10 \mathrm{mM} \mathrm{NaF}$ ) supplemented with a protease and phosphatase inhibitor cocktail (Roche). The protein concentration was detected using the BCA Kit (Pierce, IL, USA), and the protein $(50 \mu \mathrm{g})$ was separated by 10-12\% SDS-polyacrylamide gel electrophoresis and transferred onto nitrocellulose (NC) membranes. The blots were then probed with the anti-APP (Sigma) and anti-CB2 antibodies (Sigma); anti-Glyceraldehyde 3-phosphate dehydrogenase

GAPDH (Cell Signaling Technology, Boston, USA) was used as a control. The bands were visualized using the ChemiDoc XRS system (Bio-Rad, Hercules, CA, USA) and quantified with the AIDA Image software.

\section{Immunohistochemistry assay}

For the immunohistochemistry assay, $4 \%$ paraformaldehyde-fixed, paraffin-embedded tissue sections (thickness, $5 \mu \mathrm{m}$ ) were deparaffinized and rehydrated in graded alcohol. The sections were incubated overnight at $4^{\circ} \mathrm{C}$ with $2 \mu \mathrm{g} / \mathrm{ml} \mathrm{rabbit}$ anti-CB2 polyclonal antibody (Abcam, Cambridge MA, USA). Subsequently, the slides were incubated with $2 \mu \mathrm{g} / \mathrm{ml}$ biotinylated goat anti-rabbit IgG (Santa Cruz Biotechnology, Dallas, TX, USA) for $30 \mathrm{~min}$ at room temperature, and then for $30 \mathrm{~min}$ with streptavidin-horseradish peroxidase (Dako, Glostrup, Denmark). The antigen-antibody reaction was visualized with diaminobenzidine serving as the chromogen.

\section{Plasmid construction and luciferase assays}

The 3'-UTR of CB2 was amplified by PCR and inserted into the pMIRGLO luciferase reporter vector (Promega, Madison, WI). For sequence point mutations, sitedirected mutagenesis of potential target sites in the CB2 3'-UTR was performed using a QuikChange site-directed mutagenesis kit (Promega, Madison, WI, USA). For the luciferase reporter assay, the cells were seeded into a 12-well plate and co-transfected with $50 \mathrm{nM}$ miRNA mimic and $400 \mathrm{ng}$ reporter recombinant plasmid using Lipofectamine ${ }^{\mathrm{TM}} 2000$ reagent (Invitrogen, Carlsbad, CA, USA) according to the manufacturer's instructions. The luciferase activity was measured with a dual luciferase system kit (Promega) 48 $\mathrm{h}$ after transfection. The firefly luciferase activity was normalized against the renilla luciferase gene activity.

Genetics and Molecular Research 16 (1): gmr16019166 


\section{Cell marker and cytokine quantification}

The cells were labeled with fluorochrome-coupled anti-mouse cluster of differentiation 40 (CD40) and intercellular adhesion molecule 1 (ICAM) antibodies (Abcam, Cambridge MA, USA), followed by incubation with streptavidin- fluorochrome coupled secondary reagents. The immunofluorescence of labeled cells was subsequently measured using a FACS Canto II (BD Bioscience, Heidelberg, Germany). The murine interleukin 6 (IL-6) and tumor necrosis factor $\alpha$ (TNF- $\alpha$ ) ELISA kits (eBioscience, Hercules, CA, USA) were used to quantify the levels of these cytokines according to the manufacturer's protocol.

\section{Statistical analysis}

Data analyses were performed using the SPSS 17.0 software (SPSS, Inc., Chicago, IL, USA). The results are reported as means \pm standard deviation. The differences between groups were analyzed using either Student $t$-test or one-way ANOVA. Results with $\mathrm{P}<0.05$ were considered to be statistically significant.

\section{RESULTS}

\section{miR-139 expression is elevated in aged SAMP8 mice}

To test the AD model, we quantified the expression of APP in 8-month-old SAMP8 (AD model group) and SAMR1 (control group) mice. Both the APP mRNA (SAMR1 group: $1.00 \pm 0.14$, SAMP8 group: $1.42 \pm 0.08, \mathrm{P}<0.001$, Figure $1 \mathrm{~A}$ ) and protein (SAMR1 group: $1.00 \pm 0.19$, SAMP8 group: $1.64 \pm 0.22, \mathrm{P}<0.001$, Figure $1 \mathrm{~B}$ and $\mathrm{C}$ ) levels were significantly higher in the SAMP8 mice than in SAMR1 mice, indicating that the age-associated AD model was successfully established by 8 months in SAMP8 mice. Next, we measured the expression levels of miR-139 in SAMP8 and SAMR1 mice. Compared to the SAMR1 mice, the expression of miR-139 was notably up-regulated in 8-month-old SAMP8 mice (SAMR1 group: $1.49 \pm 0.08$, SAMP8 group: $2.92 \pm 0.13, \mathrm{P}<0.001$, Figure 1D).

A

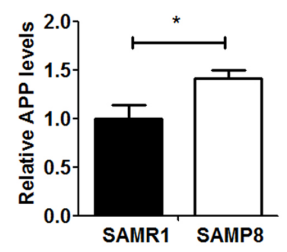

B

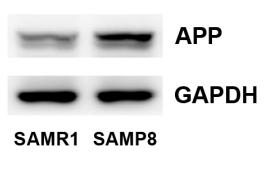

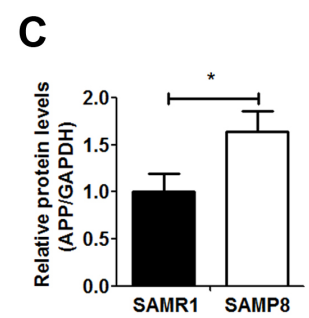

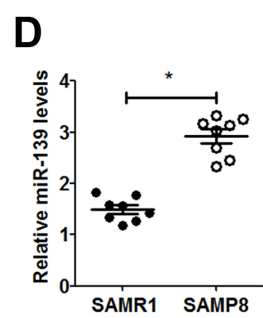

Figure 1. Enhanced miR-139 levels are observed in aged SAMP8 mice. A. The APP mRNA expression levels were determined by qPCR in the hippocampal tissue derived from 8-month-old SAMR1 and SAMP8 mice. B. Western blot analysis of the APP protein level in the hippocampal tissue derived from 8-month-old SAMR1 and SAMP8 mice. C. Quantification of the relative protein levels (APP/GAPDH) using densitometry. D. The expression levels of miR-139 measured by qPCR. Data are reported as means $\pm \mathrm{SD} ; * \mathrm{P}<0.05 ; \mathrm{N}=5$. APP, amyloid precursor protein; qPCR, quantitative polymerase chain reaction; SAMR1, senescence-accelerated mouse-resistant 1; SAMP8, senescence accelerated mouse prone 8.

Genetics and Molecular Research 16 (1): gmr16019166 


\section{miR-139 impairs the acquisition and retention of spatial memory}

To assess whether miR-139 expression exerts effects on learning and memory, we injected miR-139, anti-miR-139, and control miRNA mimics into the dentate gyrus of the SAMP8 and SAMR1 mice (SAMR1 + miR-con, SAMP8 + miR-con, SAMP8 + miR-139, SAMP8 + antimiR-139). Quantitative PCR (qPCR) analysis revealed that the miR-139 levels were remarkably elevated in the SAMP8 + miR-139 group, while being reduced in the SAMP8 + anti-miR-139 group compared to the SAMP8 + miR-con group (SAMR1 + miR-con group: $1.00 \pm 0.15$, SAMP8 + miR-con group: $1.94 \pm 0.22$, SAMP8 + miR-139 group: $3.62 \pm 0.30$, SAMP8 + anti-miR-139 group: $0.63 \pm 0.10, \mathrm{P}<0.001$, Figure $2 \mathrm{~A}$ ). The Morris water maze test revealed that even though all the mice showed lower latency times following training, mice from the SAMP8 + miR-139 group took notably longer to find the platform. In contrast, the SAMP8 + anti-miR-139 group took the least amount of time to find the platform compared to the other groups (4 day: SAMR1 + miR-con group: $22.12 \pm 2.96$, SAMP8 + miR-con group: $33.54 \pm 3.56$, SAMP8 + miR-139 group: $43.76 \pm$ 5.26, SAMP8 + anti-miR-139 group: $24.63 \pm 4.47, \mathrm{P}<0.001$, Figure $2 \mathrm{~B})$.

A

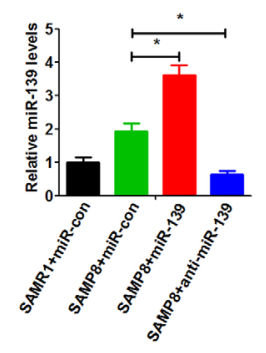

D

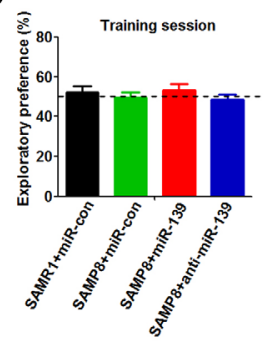

B

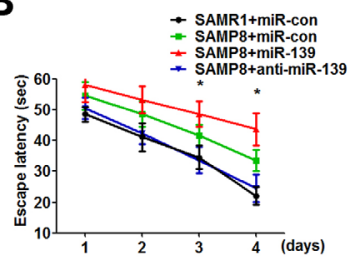

E

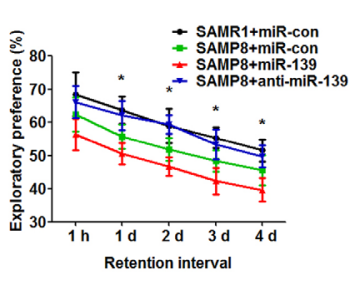

$\mathbf{C}$

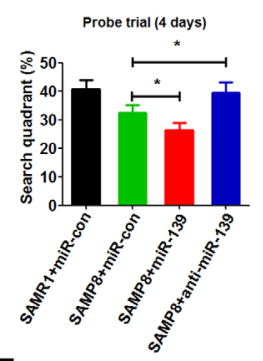

$\mathbf{F}$

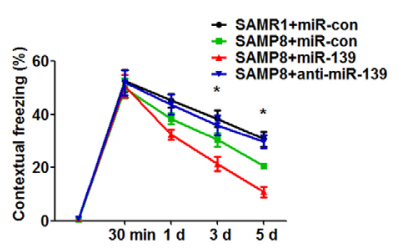

Figure 2. miR-139 regulates hippocampal function in AD mice. A. miR-139 expression measured by qPCR analysis. B. The escape latency in the Morris Water Maze over 4 days of training. C. Probe tests conducted 4 days after the acquisition phase. D. Exploratory preference in the training sessions of the novel object recognition task. The dotted line represents the performance at the chance level (50\%). E. The memory of the novel object was measured after training. F. Contextual freezing behavior was observed after exposure to the conditioned environment at the indicated time. Data are reported as means $\pm \mathrm{SD} ;{ }^{*} \mathrm{P}<0.05 ; \mathrm{N}=5$. AD, Alzheimer's disease; qPCR, quantitative polymerase chain reaction.

To test the memory retention, each trained group was tested in the probe trials on post-training day 4. During the probe tests, the SAMP8 + miR-139 group showed the lowest success rate in finding the platform, while the success rate of the SAMP8 + anti-miR-139 group was equal to that of the SAMR1 + miR-con group (4 day: SAMR1 + 
miR-con group: $40.65 \pm 3.46$, SAMP8 + miR-con group: $32.34 \pm 2.91$, SAMP8 + miR139 group: $26.58 \pm 2.31$, SAMP8 + anti-miR-139 group: $39.54 \pm 3.77, \mathrm{P}<0.001$, Figure $2 \mathrm{C})$. There was no significant difference in the swimming speed between the four groups (data not shown).

\section{miR-139 impairs novel object recognition and contextual fear conditioning}

To assess visual memory, the novel object recognition task was performed. During training, no significant differences were observed among the four groups with respect to the amount of time spent exploring the two novel objects, indicating that each group exhibited similar levels of motivation and curiosity while exploring new objects (Figure 2D). In the retention tests conducted either $1 \mathrm{~h}$ or $1-4$ day post-training, the SAMP8 + miR-139 group exhibited a much weaker preference for the novel object than the SAMP8 + miR-con group, while the SAMP8 + anti-miR-139 group exhibited a normal preference level (4 day: SAMR1 + miR-con group: $51.65 \pm 3.32$, SAMP8 + miR-con group: 45.62 \pm 4.51 , SAMP8 + miR-139 group: $39.74 \pm 3.62$, SAMP8 + anti-miR-139 group: 49.87 $\pm 3.43, \mathrm{P}<0.001$, Figure 2E). Results from the contextual fear memory test indicated no significant difference in the immediate freezing among the four groups; however, a remarkable difference was observed in contextual freezing during post-training days 1,3 , and 5. Compared to the SAMP8 + miR-con group, the SAMP8 + miR-139 group showed a reduced contextual freezing rate. However, the contextual freezing rate of the SAMP8 + anti-miR-139 group returned to the normal level (5 day: SAMR1 + miR-con group: 30.77 \pm 2.90 , SAMP8 + miR-con group: $20.73 \pm 1.01$, SAMP8 + miR-139 group: $10.88 \pm 1.93$, SAMP8 + anti-miR-139 group: $29.74 \pm 2.44, \mathrm{P}<0.001$, Figure $2 \mathrm{~F}$ ).

\section{miR-139 regulates $\mathrm{CB} 2$ expression by binding to its 3 '-UTR}

To identify molecular targets of miR-139, we used the TargetScan website (www. targetscan.org) to search for putative genetic targets of miR-139 and identified CB2 as a potential target.

Immunohistochemistry analysis showed that overexpression of miR-139 resulted in a decrease in the number of CB2-positive nuclei in the hippocampus, while down-regulation of miR-139 led to an increase in the number of CB2-positive nuclei (miR-con group: $13.45 \pm$ 2.33, miR-139 group: $5.68 \pm 1.87$, anti-miR-139 group: $27.98 \pm 3.21, \mathrm{P}<0.001$, Figure $3 \mathrm{~A}$ and $\mathrm{B})$. We further analyzed the CB2 protein expression in primary hippocampal cells following transfection, and found a significant decrease in the CB2 protein levels after transfection with miR-139 mimics, with a concomitant increase in the CB2 level after transfection with miR139 inhibitors (miR-con group: $1.00 \pm 0.17$, miR-139 group: $0.47 \pm 0.05$, anti-miR-139 group: $1.87 \pm 0.22, \mathrm{P}<0.001$, Figure $3 \mathrm{C}$ and $\mathrm{D})$.

To validate whether miR-139-mediated regulation of CB2 occurs in microglial cells, the possible target positions of the wild-type CB2 3'-UTR or mutant sequences were cloned into the pmirGLO dual-luciferase expression vector (Figure 3E). Next, we cotransfected primary hippocampal cells with miR-139, anti-miR-139, or control mimics, as well as either wild type or mutant recombinant CB2 plasmids. The results show that transfection with miR-139 mimics notably reduced the luciferase activities for wild type CB2, whereas transfection with anti-miR-139 mimics increased wild type luciferase activity. In contrast, the activity of the luciferase reporter gene linked to the 3'-UTR of

Genetics and Molecular Research 16 (1): gmr16019166 
the mutant CB2 did not change in the presence of either miR-139 or anti-miR-139 mimics (miR-con group: $1.00 \pm 0.12$, miR-139 group: $0.64 \pm 0.07$, anti-miR-139 group: $1.77 \pm$ $0.11, \mathrm{P}<0.001$, Figure 3F).

A

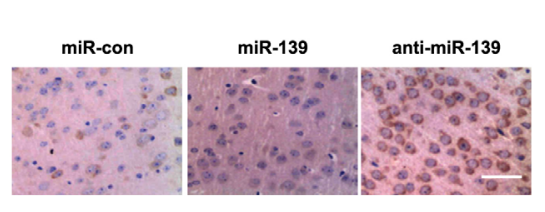

D

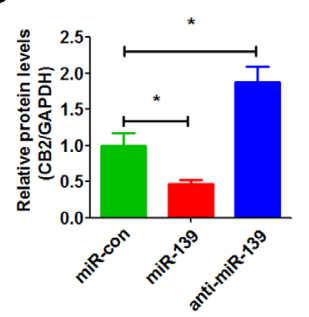

B

E

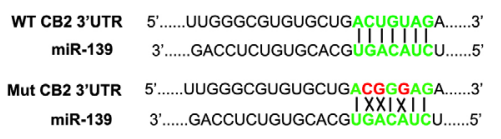

C

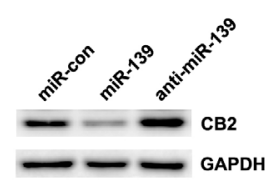

$\mathbf{F}$

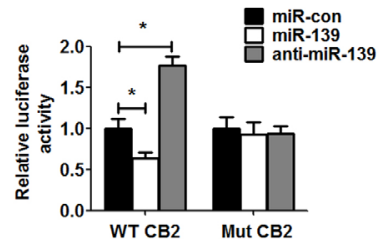

Figure 3. miR-139 targets the CB2 transcript. A. Immunohistochemistry of the miR-139 and CB2 levels in the hippocampal tissue (scale bar $=100 \mu \mathrm{m}$ ). B. Quantification of the CB2-positive cells shown in panel A. C. Western blot of the CB2 protein expression in primary hippocampal cells. D. Quantification of relative protein levels (CB2/ GAPDH) by densitometry. E. Schematic representation of the interaction of miR-139 with wild type and mutant CB2 3'-UTR. The mutant sequence was based on the wild-type plasmid with CGG instead of CUU located at the seed sequence. F. Luciferase reporter assays in primary hippocampal cells co-transfected with the wild-type 3'-UTR CB2 reporter plasmid or mutant type 3'-UTR CB2, along with miR-139, anti-miR-139, or control mimics. Data are expressed as the mean $\pm \mathrm{SD} ; * \mathrm{P}<0.05 ; \mathrm{N}=5$. $\mathrm{CB} 2$, cannabinoid receptor type 2 ; GAPDH, Glyceraldehyde 3-phosphate dehydrogenase; UTR, untranslated region.

\section{miR-139 decreases responses to proinflammatory stimuli}

We assessed the effects of miR-139 on the inflammatory responses via stimulating primary hippocampal cells with LPS/IFN $\gamma$ after transfection with miR-139, anti-miR139, or control mimics. The overexpression of miR-139 resulted in the inhibition of ICAM-1 and CD40 expression following stimulation with LPS/IFN $\gamma$ in primary cells. However, the knockdown of miR-139 induced the expression of ICAM-1 and CD40 (ICAM-1: miR-con group: $4.51 \pm 0.45$, miR-139 group: $3.15 \pm 0.36$, anti-miR-139 group: $5.89 \pm 0.47, \mathrm{P}<0.001$; CD40: miR-con group: $1.23 \pm 0.13$, miR-139 group: $0.64 \pm 0.08$, anti-miR-139 group: $1.94 \pm$ $0.18, \mathrm{P}<0.001$, Figure $4 \mathrm{~A}$ and $\mathrm{B}$ ). In addition, cytokine release was analyzed after stimulation with LPS/IFN $\gamma$. We observed significantly lower production of IL-6 and TNF- $\alpha$ in miR-139overexpressing cells and higher levels of these cytokines in miR-139-low-expressing cells (IL-6: miR-con group: $7.46 \pm 0.44$, miR-139 group: $5.18 \pm 0.22$, anti-miR-139 group: 9.14 $\pm 0.54, \mathrm{P}<0.001$; TNF- $\alpha$ : miR-con group: $2.03 \pm 0.21$, miR-139 group: $1.57 \pm 0.13$, antimiR-139 group: $2.79 \pm 0.30, \mathrm{P}<0.001$, Figure $4 \mathrm{C}$ and $\mathrm{D}$ ). 

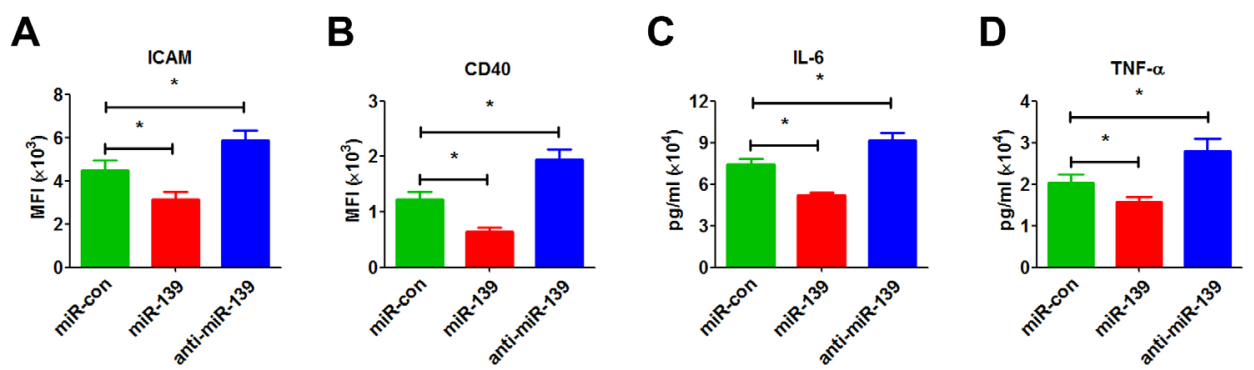

Figure 4. miR-139 inhibits the expression of LPS/IFN $\gamma$-induced proinflammatory cell surface markers and inflammatory cytokine expression in primary hippocampal cells. Primary hippocampal cells were transfected with miR-139, anti-miR-139, or control mimics for $48 \mathrm{~h}$. The cells were then treated with LPS $(100 \mathrm{ng} / \mathrm{mL})$ and IFN $\gamma$ $(20 \mathrm{ng} / \mathrm{mL})$ for $12 \mathrm{~h}$. A. B. The expression of ICAM and CD44 detected by flow cytometry. C. D. The levels of IL- 6 and TNF- $\alpha$ measured by ELISA. Data are reported as means $\pm \mathrm{SD} ; * \mathrm{P}<0.05 ; \mathrm{N}=5$. LPS, lipopolysaccharide; IFN $\gamma$, interferon $\gamma$; ICAM, intercellular adhesion molecule 1; CD44, cluster of differentiation 40; IL-6, interleukin 6 ; TNF- $\alpha$, tumor necrosis factor $\alpha$; ELISA, enzyme-linked immunosorbent assay.

\section{DISCUSSION}

$\mathrm{AD}$ is one of the most common diseases in the elderly population. Previous studies have devoted a great deal of attention to protein changes that occur in $\mathrm{AD}$, and their relation to pathogenesis with respect to the onset and development of AD. However, recent research suggests that miRNAs play an important role in the molecular pathogenesis of both genetic and sporadic AD (Berezin et al., 2014). The expression profile of miRNAs in patients with $\mathrm{AD}$ is significantly altered compared to that in controls, and these alterations may play a direct role in regulating the expression of $\mathrm{AD}$-related genes and its subsequent phenotypic manifestations (Kiko et al., 2014).

Growing evidence suggests that miR-139 acts as a tumor suppressor during tumorigenesis, and aberrant regulation of miRNAs has been associated with various malignancies, including colorectal cancer (Shen et al., 2012), hepatocellular carcinoma (Li et al., 2014), gastric cancer (Bao et al., 2011), and parathyroid malignancies (Corbetta et al., 2010). Our study is the first to publish miRNA-139 expression profiles in the hippocampus of an AD mouse model. Abnormalities in the expression levels of miRNAs such as miR206 and miR-34c have been shown to impair associative learning in mouse models of AD (Zovoilis et al., 2011; Lee et al., 2012). To explore the effects of miR-139 on learning and memory, we overexpressed and inhibited the expression of miR-139 by hippocampal injection of miRNAs. Our study strongly suggests that miR-139 modulates hippocampalassociated learning and memory processes. The down-regulation of miR-139 expression improved spatial memory, novel object recognition, and long-term memory of contextual fear conditioning in the SAMP8 mouse model of AD.

To understand the mechanisms underlying the effects of miR-139 in AD, we investigated the potential targets of miR-139. Immunohistochemical analysis revealed an inverse relationship between the miR-139 and CB2 expression levels. Furthermore, luciferase reporter assays verified that miR-139 inhibits CB2 expression by directly binding to its 3'-UTR. $\mathrm{CB} 2$, an alternative membrane marker of activated microglial cells, is currently regarded as a critical protein which triggers multiple brain pathophysiological events involved in synaptic plasticity and neuroprotection (Chiurchiù et al., 2015). Several lines of evidence have offered 
new perspectives on the possible involvement of $\mathrm{CB} 2$ signaling in brain and spinal cord traumatic injury, as well as in several neurodegenerative disorders, including AD (Ahmad et al., 2016; Bisogno et al., 2016). These studies support the possibility that CB2 is part of a protective mechanism that is both acutely and chronically activated during neuropathology.

In $\mathrm{AD}$, microglial cells cluster around dense core amyloid plaques (Itagaki et al., 1989), the major neuropathological hallmark of $\mathrm{AD}$, and are thought to be toxic to the surrounding neural tissue (Spires et al., 2005; Busche et al., 2008; Kuchibhotla et al., 2008; Meyer-Luehmann et al., 2009). Microglia activated in vitro induce the expression of proinflammatory cytokines, including IL-6, IL-8, TNF- $\alpha$, reactive oxygen/nitrogen species, and chemokines, all of which are known to cause neuronal damage (Van Eldik et al., 2007; Zaheer et al., 2008; Fernández et al., 2013). Studies on brain tissue derived from patients with $\mathrm{AD}$ have shown that $\mathrm{CB} 2$ modulates hippocampal function in the context of $\mathrm{AD}$ pathology (Benito et al., 2003). CB2 deficiency was shown to affect both the ability to activate microglia and the recruitment of macrophages into the brains of AD mice (Schmöle et al., 2015). Furthermore, pharmacological studies in rodents have also suggested that CB2 plays a crucial role in $\mathrm{AD}$-associated inflammatory responses (Wu et al., 2013). The CB2-deficient microglial cells showed decreased responses to stimulation with LPS/IFN $\gamma$ as well as reduced expression levels of proinflammatory cell surface markers (Ehrhart et al., 2005). Our results are consistent with previous studies demonstrating that CB2 deficiency results in reduced neuroinflammation in AD. Our data are the first to reveal that miR-139 decreases responses to proinflammatory stimuli and acts as a regulatory factor in $\mathrm{AD}$ pathogenesis by downregulating CB2 expression. However, miR-139 might target many other pathways contributing to the AD phenotype. Prospective studies should further evaluate the potential of miR-139 in developing multimodal drug approaches to treat patients with $\mathrm{AD}$.

In summary, we elucidated the potential mechanism underlying the upregulation of $\mathrm{CB} 2$ in $\mathrm{AD}$. We also demonstrated that the attenuation of CB2-mediated inflammatory responses is possible through the modulation of miR-139 expression. Thus, miR-139 may be a promising therapeutic target in multimodal drug approaches to treat $\mathrm{AD}$ progression.

\section{Conflicts of interest}

The authors declare no conflicts of interest.

\section{REFERENCES}

Abe M and Bonini NM (2013). MicroRNAs and neurodegeneration: role and impact. Trends Cell Biol. 23: 30-36. http:// dx.doi.org/10.1016/j.tcb.2012.08.013

Ahmad R, Postnov A, Bormans G, Versijpt J, et al. (2016). Decreased in vivo availability of the cannabinoid type 2 receptor in Alzheimer's disease. Eur. J. Nucl. Med. Mol. Imaging 43: 2219-2227. http://dx.doi.org/10.1007/s00259$\underline{016-3457-7}$

Banzhaf-Strathmann J, Benito E, May S, Arzberger T, et al. (2014). MicroRNA-125b induces tau hyperphosphorylation and cognitive deficits in Alzheimer's disease. EMBO J. 33: 1667-1680. http://dx.doi.org/10.15252/embj.201387576

Bao W, Fu HJ, Xie QS, Wang L, et al. (2011). HER2 interacts with CD44 to up-regulate CXCR4 via epigenetic silencing of microRNA-139 in gastric cancer cells. Gastroenterology 141: 2076-2087.e6. http://dx.doi.org/10.1053/j. gastro.2011.08.050

Bekris LM, Yu CE, Bird TD and Tsuang DW (2010). Genetics of Alzheimer disease. J. Geriatr. Psychiatry Neurol. 23: 213-227.http://dx.doi.org/10.1177/0891988710383571

Benito C, Núñez E, Tolón RM, Carrier EJ, et al. (2003). Cannabinoid CB2 receptors and fatty acid amide hydrolase are selectively overexpressed in neuritic plaque-associated glia in Alzheimer's disease brains. J. Neurosci. 23: 11136-11141.

Genetics and Molecular Research 16 (1): gmr16019166 
Berezin V, Walmod PS, Filippov M and Dityatev A (2014). Targeting of ECM molecules and their metabolizing enzymes and receptors for the treatment of CNS diseases. Prog. Brain Res. 214: 353-388. http://dx.doi.org/10.1016/B978-0444-63486-3.00015-3

Bisogno T, Oddi S, Piccoli A, Fazio D, et al. (2016). Type-2 cannabinoid receptors in neurodegeneration. Pharmacol. Res. 111: 721-730. http://dx.doi.org/10.1016/j.phrs.2016.07.021

Burns A and Iliffe S (2009). Alzheimer's disease. BMJ 338: b158. http://dx.doi.org/10.1136/bmj.b158

Busche MA, Eichhoff G, Adelsberger H, Abramowski D, et al. (2008). Clusters of hyperactive neurons near amyloid plaques in a mouse model of Alzheimer's disease. Science 321: 1686-1689.http://dx.doi.org/10.1126/science.1162844

Chiurchiù V, Leuti A and Maccarrone M (2015). Cannabinoid Signaling and Neuroinflammatory Diseases: A Melting pot for the Regulation of Brain Immune Responses. J. Neuroimmune Pharmacol. 10: 268-280. http://dx.doi.org/10.1007/ $\underline{\text { s11481-015-9584-2 }}$

Corbetta S, Vaira V, Guarnieri V, Scillitani A, et al. (2010). Differential expression of microRNAs in human parathyroid carcinomas compared with normal parathyroid tissue. Endocr. Relat. Cancer 17: 135-146. http://dx.doi.org/10.1677/ ERC-09-0134

Ehrhart J, Obregon D, Mori T, Hou H, et al. (2005). Stimulation of cannabinoid receptor 2 (CB2) suppresses microglial activation. J. Neuroinflammation 2: 29. http://dx.doi.org/10.1186/1742-2094-2-29

Fernández PL, Britton GB and Rao KS (2013). Potential immunotargets for Alzheimer's disease treatment strategies. $J$. Alzheimers Dis. 33: 297-312.

Hébert SS and De Strooper B (2009). Alterations of the microRNA network cause neurodegenerative disease. Trends Neurosci. 32: 199-206. http://dx.doi.org/10.1016/j.tins.2008.12.003

Itagaki S, McGeer PL, Akiyama H, Zhu S, et al. (1989). Relationship of microglia and astrocytes to amyloid deposits of Alzheimer disease. J. Neuroimmunol. 24: 173-182.http://dx.doi.org/10.1016/0165-5728(89)90115-X

Jeon D, Yang YM, Jeong MJ, Philipson KD, et al. (2003). Enhanced learning and memory in mice lacking $\mathrm{Na}^{+} / \mathrm{Ca}^{2+}$ exchanger 2. Neuron 38: 965-976. http://dx.doi.org/10.1016/S0896-6273(03)00334-9

Kiko T, Nakagawa K, Tsuduki T, Furukawa K, et al. (2014). MicroRNAs in plasma and cerebrospinal fluid as potential markers for Alzheimer's disease. J. Alzheimers Dis. 39: 253-259.

Kim VN, Han J and Siomi MC (2009). Biogenesis of small RNAs in animals. Nat. Rev. Mol. Cell Biol. 10: 126-139.http:// dx.doi.org/10.1038/nrm2632

Kuchibhotla KV, Goldman ST, Lattarulo CR, Wu HY, et al. (2008). Abeta plaques lead to aberrant regulation of calcium homeostasis in vivo resulting in structural and functional disruption of neuronal networks. Neuron 59: 214-225. http://dx.doi.org/10.1016/j.neuron.2008.06.008

Lee ST, Chu K, Jung KH, Kim JH, et al. (2012). miR-206 regulates brain-derived neurotrophic factor in Alzheimer disease model. Ann. Neurol. 72: 269-277. http://dx.doi.org/10.1002/ana.23588

Li T, Yin J, Yuan L, Wang S, et al. (2014). Downregulation of microRNA-139 is associated with hepatocellular carcinoma risk and short-term survival. Oncol. Rep. 31: 1699-1706.

Mendiola-Precoma J, Berumen LC, Padilla K and Garcia-Alcocer G (2016). Therapies for Prevention and Treatment of Alzheimer's Disease. BioMed Res. Int. 2016: 2589276. http://dx.doi.org/10.1155/2016/2589276

Meyer-Luehmann M, Mielke M, Spires-Jones TL, Stoothoff W, et al. (2009). A reporter of local dendritic translocation shows plaque- related loss of neural system function in APP-transgenic mice. J. Neurosci. 29: 12636-12640. http:// dx.doi.org/10.1523/JNEUROSCI.1948-09.2009

Querfurth HW and LaFerla FM (2010). Alzheimer's disease. N. Engl. J. Med. 362: 329-344. http://dx.doi.org/10.1056/ NEJMra0909142

Ren A, Zhang H, Xie Z, Ma X, et al. (2012). Regulation of hippocampus-dependent memory by the zinc finger protein Zbtb20 in mature CA1 neurons. J. Physiol. 590: 4917-4932.http://dx.doi.org/10.1113/jphysiol.2012.234187

Sang N, Zhang J, Marcheselli V, Bazan NG, et al. (2005). Postsynaptically synthesized prostaglandin E2 (PGE2) modulates hippocampal synaptic transmission via a presynaptic PGE2 EP2 receptor. J. Neurosci. 25: 9858-9870. http://dx.doi. org/10.1523/JNEUROSCI.2392-05.2005

Schmöle AC, Lundt R, Ternes S, Albayram Ö, et al. (2015). Cannabinoid receptor 2 deficiency results in reduced neuroinflammation in an Alzheimer's disease mouse model. Neurobiol. Aging 36: 710-719. http://dx.doi. org/10.1016/j.neurobiolaging.2014.09.019

Shen K, Liang Q, Xu K, Cui D, et al. (2012). MiR-139 inhibits invasion and metastasis of colorectal cancer by targeting the type I insulin-like growth factor receptor. Biochem. Pharmacol. 84: 320-330. http://dx.doi.org/10.1016/j. bcp.2012.04.017

Spires TL, Meyer-Luehmann M, Stern EA, McLean PJ, et al. (2005). Dendritic spine abnormalities in amyloid precursor

Genetics and Molecular Research 16 (1): gmr16019166 
protein transgenic mice demonstrated by gene transfer and intravital multiphoton microscopy. J. Neurosci. 25: 72787287. http://dx.doi.org/10.1523/JNEUROSCI.1879-05.2005

Van Eldik LJ, Thompson WL, Ralay Ranaivo H, Behanna HA, et al. (2007). Glia proinflammatory cytokine upregulation as a therapeutic target for neurodegenerative diseases: function-based and target-based discovery approaches. Int. Rev. Neurobiol. 82: 277-296.http://dx.doi.org/10.1016/S0074-7742(07)82015-0

Wang JH, Cheng XR, Zhang XR, Wang TX, et al. (2016). Neuroendocrine immunomodulation network dysfunction in SAMP8 mice and PrP-hAbPPswe/PS1DE9 mice: potential mechanism underlying cognitive impairment. Oncotarget 7: 22988-23005.

Wu J, Bie B, Yang H, Xu JJ, et al. (2013). Activation of the CB2 receptor system reverses amyloid-induced memory deficiency. Neurobiol. Aging 34: 791-804. http://dx.doi.org/10.1016/j.neurobiolaging.2012.06.011

Zaheer A, Zaheer S, Thangavel R, Wu Y, et al. (2008). Glia maturation factor modulates beta-amyloid-induced glial activation, inflammatory cytokine/chemokine production and neuronal damage. Brain Res. 1208: 192-203. http:// dx.doi.org/10.1016/j.brainres.2008.02.093

Zovoilis A, Agbemenyah HY, Agis-Balboa RC, Stilling RM, et al. (2011). microRNA-34c is a novel target to treat dementias. EMBO J. 30: 4299-4308.http://dx.doi.org/10.1038/emboj.2011.327

Genetics and Molecular Research 16 (1): gmr16019166 